\title{
Should Age Be Part of Multidimensional Indices of Risk in Chronic Obstructive Pulmonary Disease?
}

\author{
Juan P. de-Torres ${ }^{a}$ Marc Miravitlles ${ }^{b}$ \\ a Pulmonary Department, Clínica Universidad de Navarra, Pamplona, and b Pneumology Department, Hospital \\ Universitari Vall d'Hebron, CIBER de Enfermedades Respiratorias (CIBERES), Barcelona, Spain
}

Until very recently, the prognostic evaluation of chronic obstructive pulmonary disease (COPD) was based exclusively on the degree of airflow limitation [1]. However, COPD has an impact on different clinical domains (symptoms, exercise capacity, nutritional, inflammatory, etc.) and is associated with frequent comorbidities. The last revision of the Global Initiative for Obstructive Lung Diseases (GOLD) recognized the complexity of COPD and recommended its multidimensional evaluation, including not only the degree of airflow obstruction (FEV1\%) but also the number of exacerbations in the previous year and the presence of symptoms evaluated by the modified Medical Research Council (mMRC) dyspnea scale or the COPD Assessment test [2].

In an attempt to further improve the prognostic evaluation of COPD patients 10 years ago, an international group of investigators proposed the first multidimensional evaluation of COPD patients: the BODE index (body mass index, airway obstruction represented by the FEV1\%, dyspnea measured by the mMRC, and exercise capacity evaluated by the 6 -minute walking test) [3]. They demonstrated that the BODE predicted all-cause and respiratory mortality at 3 years much better than FEV1\% alone. Since then, several modifications of the BODE index (eBODE, BODEx, mBODE) and other indices, such as the ADO, DOSE, HADO, CPI, etc., have been developed and validated as potential multidimensional tools to evaluate the risk of mortality in COPD patients [4].

The ADO index (age, dyspnea, and airway obstruction) was first proposed and validated by Puhan et al. [5] in two different COPD cohorts: a Swiss population of severe COPD and a Spanish population of COPD recruited after their first admission for a COPD exacerbation. In a recent issue of Respiration, Abu Hussein et al. [6] explored the prognostic value of the ADO in two different populations of a general practice based on COPD patients from the Netherlands and Switzerland followed for at least 24 months. They found that the ADO showed an excellent discrimination capacity (AUC 0.79 in the Dutch cohort and 0.76 in the Swiss cohort) for all-cause mortality. These findings are potentially important and suggest that ADO may help in the clinical evaluation of COPD patients by general practitioners, but does it help in everyday clinical practice?

With the proliferation of multidimensional indices, it is crucial to identify those that are better prognosticators and that may help clinicians in their daily practice. BODE is the most widely used and validated index but has the potential limitation of the implementation of the 6-minute walking test at the general practice level. In contrast,

\section{KARGER 125}

(c) 2015 S. Karger AG, Base

0025-7931/15/0894-0274\$39.50/0
Juan P. de-Torres

Pulmonary Department

Clínica Universidad de Navarra, Av Pio XII, 36

ES-31008 Pamplona (Spain)

E-Mail jupa65@hotmail.com 
the ADO index includes simple parameters (age, dyspnea, and FEV1\%) that can be easily obtained by general practitioners and are now validated in this setting by Abu Hussein et al. [6]. However, age is, obviously, nonmodifiable, and COPD is a disease with nonreversible obstruction. In fact, in $80-90 \%$ of the patients, the FEV $1 \%$ remains the same or declines over time [7]. Therefore, the only modifiable parameter of ADO is dyspnea. This characteristic of $\mathrm{ADO}$ does not support its use for helping in therapeutic decisions and should only be applied for mortality risk assessment, as recognized by the authors [6]. The inclusion of age in a multicomponent index is controversial. Older age is obviously linked to an increased risk of mortality, not only in chronic diseases but also in healthy individuals; it cannot be modified by interventions and is not a characteristic of COPD. Furthermore, Marin et al. [4] demonstrated that BODE and its different variants had a better predictive value for mortality than ADO after age adjustment, showing that age has an important weight in the predictive capacity for mortality in the ADO index. According to these results, BODE and its variants would be the most informative indices, and age should always be considered independently. For instance, a 45 -year-old COPD patient with a BODE 7 will have a better prognosis than an 85-year-old patient with the same BODE 7. Due to its demonstrated predictive value, the Spanish guideline for COPD (GesEPOC) has been the first guideline to incorporate the BODE/BODEx as the measure of severity in addition to the classification of COPD patients by clinical phenotypes [8].

Although the data by Abu Hussein et al. [6] support the potential use of ADO for mortality risk assessment at the general practitioner level, the value of ADO in everyday clinical practice is still not clear.

\section{References}

-1 Rabe KF, Hurd S, Anzueto A, Barnes PJ, Buist SA, Calverley P, Fukuchi Y, Jenkins C, Rodriguez-Roisin R, van Weel C, Zielinski J: Global strategy for the diagnosis, management, and prevention of chronic obstructive pulmonary disease: GOLD executive summary. Am J Respir Crit Care Med 2007;176:532-555.

$\checkmark 2$ Vestbo J, Hurd SS, Agustí AG, Jones PW, Vogelmeier C, Anzueto A, Barnes PJ, Fabbri LM, Martinez FJ, Nishimura M, Stockley RA, Sin DD, Rodriguez-Roisin R: Global strategy for the diagnosis, management, and prevention of chronic obstructive pulmonary disease: GOLD executive summary. Am J Respir Crit Care Med 2013;187:347-365.

$>3$ Celli BR, Cote C, Marin JM, Casanova C, Montes de Oca M, Mendez RA, Pinto Plata V, Cabral HJ: The body mass index, airflow obstruction, dyspnea, and exercise capacity in- dex in chronic obstructive pulmonary disease. N Engl J Med 2004;350:1005-1012.

-4 Marin JM, Alfageme I, Almagro P, Casanova C, Esteban C, Soler-Cataluña JJ, de Torres JP, Martínez-Cambor P, Miravitlles M, Celli BR, Soriano JB: Multicomponent indices to predict survival in COPD: the COCOMICS study. Eur Respir J 2013;42:323-332.

5 Puhan MA, Garcia-Aymerich J, Frey M, ter Riet G, Antó JM, Agustí AG, Gomez FP, Rodriguez-Roisin R, Moons KG, Kessels AG, Held U: Expansion of the prognostic assessment of patients with chronic obstructive pulmonary disease: the updated BODE index and the ADO index. Lancet 2009;374:704-711.

-6 Abu Hussein N, ter Riet G, Schoenenberger L, Bridebaux P-O, Chhajed PN, Fitting J-W, Geiser T, Jochmann A, Joos Zellweger L, Kohler M, Maier S, Miedinger D, Schafroth Török S,
Scherr A, Siebeling L, Thurnheer R, Tamm M, Puhan MA, Leuppi JD: The ADO index as a predictor of two-year mortality in general practice-based chronic obstructive pulmonary disease cohorts. Respiration 2014;88:208-214.

$>7$ Casanova C, Aguirre-Jaíme A, de Torres JP, Pinto-Plata V, Baz R, Marin JM, Divo M, Cordoba E, Basaldua S, Cote C, Celli BR: Longitudinal assessment in COPD patients: multidimensional variability and outcomes. Eur Respir J 2014;43:745-753.

$>8$ Miravitlles M, Soler-Cataluña JJ, Calle M, Molina J, Almagro P, Quintano JA, Riesco JA, Trigueros JA, Piñera P, Simón A, RodríguezHermosa JL, Marco E, López D, Coll R, CollFernández R, Lobo MA, Díez J, Soriano JB, Ancochea J: Spanish guideline for COPD (GesEPOC). Update 2014. Arch Bronconeumol 2014;50(suppl 1):1-16. 